\title{
Exercise against tumor- and chemotherapy-induced muscle wasting
}

\author{
Dario Coletti* \\ Sorbonne Université, Biology of Adaptation and Aging, B2A, F-75005, Paris, France; Sapienza University of Rome, Dept. of Anatomy, Histology, Forensic \\ Medicine and Orthopedics, 00161, Rome Italy
}

\begin{abstract}
Cancer cachexia is a severe muscle wasting syndrome associated to cancer and distinct from anorexia, which is often present in this condition. Muscle wasting is exacerbated in cancer patients by chemotherapy treatments. Indeed, chemotherapy itself can induce muscle wasting in animal models in the absence of cancer. Exercise is currently proposed in multimodal therapies for cancer patients. Both endurance and resistance exercise are safe and do not seem to provoke further damage to a frail muscle tissue due to tumor dependent dystrophin downregulation. Through its pleiotropic effects, the benefits of exercise spam from a shift from pro- to anti-inflammatory cytokines, to direct effects on muscle fibers, such as an amelioration of the autophagic flux and pathways involved in protein metabolism. In addition, exercise positively affects the muscle stem cell niche, favoring a pro-myoogenic environment. Since tumor- and chemotherapy-induced muscle wasting share molecular mechanisms, exercise may have the potential to counteract both disease- and therapy-related side effects and to rescue muscle homeostasis.
\end{abstract}

\section{Introduction}

Cancer-cachexia is a syndrome characterized by a severe decrease of body weight, accounted for by specific loss of skeletal muscle and adipose tissues. Cachexia, which is distinct from anorexia, is due to a combination of reduced food intake and metabolic changes, including high energy expenditure, excess catabolism and inflammation [1]. Cachexia is linked to the production of cytokines by the tumor itself or the immune system of the host, which play a major role in the regulation of muscle wasting [2]. Pro-inflammatory cytokines, such as IL-6, act as double-edged swords since they recruit NK cells to attack tumor cells [3], but also induce a systemic metabolic stress response that blocks the effects of anti-cancer immunotherapy [4]. The pivotal role of fat tissue in driving the chronic inflammation that triggers cachexia was recently recognized [5, 6]. Skeletal muscle tissue is enriched in various stem cells but not in inflammatory cells in cachexia [7]; nonetheless, it is a primary target of pro-inflammatory cytokines, which induce muscle fiber atrophy and stem cell dysregulation and apoptosis [8-10].

Cachexia is associated to a large extent with cancers of the pancreas, esophagus, stomach, lung, liver and bowel; this group of malignancies is responsible for $50 \%$ of all cancer deaths worldwide [1] and cachexia is directly accountable for the death of about $20 \%$ of all cancer patients [11]. Being associated with poor prognosis and a lower quality of life for patients, cachexia remains a major challenge in the management of cancer patients to date.

Muscle wasting in cachexia affects striated muscles [12, 13], with important gender differences, likely linked to sex hormones [14]. Great progress is being made in the understanding of the molecular mechanisms underlying muscle wasting, with a central role played by proteasome-mediated protein degradation [15]. As a consequence, several treatments are now being proposed to specifically counteract muscle wasting [16-18].

Chemotherapy remains the elective treatment for different cancers since it directly induces the death of tumor cells and helps endogenous host responses against cancer [19]. However, chemoterapy may induce muscle wasting, too, and loss of skeletal muscle during chemotherapy is prognostic of poor survival [20]. Consequently controlling muscle wasting especially in chemotherapy-treated patients is of the greatest importance. In spite of this, few studies have investigated this phenomenon up to date.

In this concise review the effects of exercise on cancer- and chemotherapy-induced muscle wasting are discussed.

\section{Cachexia as a multisystemic syndrome: the relevance of tissue-tissue interactions}

Although cachexia is characterized above all by fat and lean body mass wastage, fat and skeletal muscle tissues are unlikely to be the only tissues directly involved in this multifactorial, complex syndrome.

${ }^{\star}$ Correspondence to: Dario Coletti, Institute of Biology Paris-Seine, B2A Biological Adaptation and Ageing, 7 quai St Bernard, bat A, 6eme étage, case courrier 256, 75252 Paris Cedex 5, Franc,. Tel. +33 (0) 1442734 75; Fax +33 (0) 1442721 35; E-mail dario.coletti@upmc.fr

Key words: cancer cachexia, skeletal muscle atrophy, cisplatin, Folfiri, colon cancer C26

Special Issue: Assisted Exercise

Ugo Carraro

Interdepartmental Center of Myology

University of Padova

Italy

Paolo Gargiulo

Inst. f. Biomed. and Neural

Engineering / Biomed Technology Centre

Reykjavik University \& Landspitali Reykjavik

Iceland

Received: May 14, 2018; Accepted: May 23, 2018; Published: May 28, 2018 
The neuroendocrinology of the cachectic response to chronic illness is well known and has recently been reviewed by Weekers [21]. As far as skeletal muscle wasting is concerned, there appears to be a marked interaction with at least two other tissues, i.e. fat and the intestinal epithelium. Fat tissue is the primary energy store and an important endocrine organ, which in turn affects muscle homeostasis. High fat content (not simply BMI) correlates with a lower risk of mortality and decreased weight loss from lean tissue $(22,23)$. While decreased food intake due to anorexia is widely recognized as a contributing factor to the negative balance of muscle homeostasis in cachexia, the role of poor absorption of nutrients by the intestine was highlighted more recently. The proposed model is a vicious circle in which organ failure induces chronic inflammation, which in turn damages the intestinal barrier. The intestinal mucosa becomes infected by a wide range of bacteria. LPS may further exacerbate the damage to the mucosa, which in turn leads to reduced efficiency in nutrient absorption [24]. It is becoming consistently clear that systemic inflammation could be considered the common denominator of the many clinical and metabolic consequences of the cachexia syndrome. Chronic physical exercise has been associated with down regulation of inflammation $[25,26]$ and suggested as a nonpharmacological strategy for both the prevention and treatment of several chronic diseases [27]. Aerobic training in particular, has been implicated with reduction of systemic inflammation [28]. Bearing in mind that cachexia is systemic, and that muscle wasting is but one of the many symptoms of the syndrome, it appears that any efforts aiming at attenuating its effects should be envisaged as to affect the organism as a whole. It seems quite clear that strategies which are simply designed to prevent muscle loss fail to reverse other aspects of the condition, despite the specific improvements reported. It has thus been proposed to adopt exercise training as a strategy to overcome systemic inflammation in cachexia, therefore counteracting muscle wasting.

\section{Why exercise is effective against cancer-induced muscle wasting}

Resistance exercise training is defined as multiple repetitions of static or dynamic muscular contractions performed against a high load or resistance. Resistance training increases muscle mass in healthy subjects and attenuates muscle wasting associated with ageing [29]. Endurance exercise training consists of performing low- to mediumintensity exercise for long periods of time. Endurance training (such as running, cycling, or swimming) involves the use of several large groups of muscles and tends to be aerobic. Adaptations to endurance exercise include improved oxygen delivery to muscles and their increased oxidative capacity [30]. There are many clinically relevant reasons to recommend exercise for patient populations. Exercise training 1) will attenuate the physical deconditioning that patients typically experience upon diagnosis; 2) may optimize functioning when used as adjunctive therapy to standard pharmacological or surgical treatments; 3 ) may reduce secondary cardiovascular risk factors and attenuate other clinical consequences of the disease and/or treatment; 4) will optimize quality of life and possibly improve overall outcomes by improving physical functioning.

Although there are good reasons to recommend regular exercise in patient populations, this is not a straightforward endeavor in patients with chronic disease. In fact, physical exercise is also known to induce an acute inflammatory response and oxidative stress in healthy subjects as well as in patients [31]. A major concern regarding the use of exercise is exercise-induced damage. For instance, in Rheumatoid Arthritis (RA) the concern that inflamed joints might be exposed to mechanical damage during exercise is widely diffuse. In cancer cachexia a deregulation of the dystrophindistroglycan complex has been reported suggesting that the skeletal muscle is particularly exposed to mechanical damage in these patients [32]. From the above the question arises whether to exercise or not to exercise in cachexia. With the aim of addressing this therapeutic dilemma, we performed a meta-analysis on scientific studies from the last decade dealing with exercise performed by cachectic patients [33]. We observed differential effects exerted by exercise, depending on the pathology considered and the kind of exercise performed: a global positive effect of exercise was observed when all the pathologies considered were pooled together; also, a significantly positive effect of exercise was observed in patients affected by RA. On the contrary, when RA was excluded from the analysis the effects of exercise on cachexia were not significant. Considering separately the kind of exercises performed, it is interesting to observe how resistance exercise had positive, statistically significant effects on cachexia as opposed to endurance exercise [33]. However, several publications followed this metanalysis paper highlighting the beneficial effects of endurance exercise.

For instance, to further investigate the beneficial effects of exercise on cancer cachexia, our group exploited an animal model of cancer cachexia (tumor-bearing mice doing wheel running) and we showed that endurance exercise totally rescues muscle wasting [34]. In particular, we found that cancer triggers the induction of the autophagic markers LC3b and p62 in skeletal muscle in both mice and carcinoma patients. This scenario looks deleterious to muscle as well as to other tissues; however, in a counterintuitive manner, autophagy is not deleterious per se as a mechanism of muscle tissue catabolism: it is the block of autophagy progression which occurs in the presence of a cancer which dysregulates muscle metabolism contributing to muscle wasting. With this reasoning, we gave to tumor-bearing mice pharmacological treatments that promote autophagy and we noticed that they restored muscle homeostasis by modulating autophagy in cancer cachexia [34]. In the same context, we showed that aerobic exercise or exercise mimetics (AICAR) promoted autophagy and had comparable, beneficial effects on muscle homeostasis. These observations shed light on a possible mechanism underlying the beneficial effects observed in cancer patients who perform a moderate amount of physical activity, and highlight the role of autophagy-triggering drugs as a potential therapeutic approach to treating cancer patients.

In addition, in skeletal muscle endurance exercise regulates ubiquitin ligase activity [34], increases Heat shock protein 60 and induces peroxisome proliferator- activated receptor gamma coactivator a1 expression [35]. Endurance exercise also affects the muscle fiber niche and promotes satellite cell myogenic differentiation [36]. At organismal level, exercise has beneficial, immunological and hormonal effects $[37,38]$. For the all above, endurance exercise is now proposed as a treatment for cancer cachexia [39].

\section{Exercise and the side effects of chemotherapy}

In the paper entitled "Chemotherapy-induced muscle wasting: association with NF- $\kappa \mathrm{B}$ and cancer cachexia» the group headed by Denis Guttridge, at the Ohio State University, studied the effects of cisplatin, a common anti-cancer therapeutic agent, in a cancer cachexia animal model. The latter consisted in mice bearing a subcutaneously grafted colon carcinoma, the C26 tumor (40). Guttridge and co-workers found that «although cisplatin is able to reduce tumor burden as expected, muscle wasting in mice nevertheless persists. Strikingly, cisplatin alone was seen to regulate muscle atrophy, which was independent of the 
commonly implicated ubiquitin proteasome system» (Damrauer et al., in press) This study appeared for the first time in Basic and Applied Myolgy in 2008 and for its relevance is now republished in European Journal of Translational Myology in 2018. It is worth noting that then another group had reported opposite findings, i.e. that chemotherapy inhibits protein breakdown and promotes protein synthesis [41, 42], however, both studies showed that cisplatin induced body weight loss and muscle wasting in healthy mice, suggesting that chemotherapy does indeed induce muscle loss. Very likely, cisplatin triggers multiple responses in muscle tissue, which ultimately lead to muscle fiber atrophy while the role of protein ubiquitination and proteasomemediated degradation remains controversial. Clearly these studies were relevant in addressing cancer cachexia in the presence of chemotherapy, which contributes to mimicking clinical settings better.

As mentioned above, Guttridge's laboratory did not suggest a role for proteasome-mediated protein degradation during chemotherapy, while Attaix's group found that chemotherapy reduced proteasomedependent protein degradation, both in the absence or presence of a tumor [41] (see also Damrauer et al., in press). A possible explanation is that the first group did not directly measure proteasome activity, but rather Murf1 expression. Murf1 is a muscle specific ubiquitin ligase which leads proteins to the proteasome, but it is not unique in its role and could be redundant with other ubiquitin-ligases, such as Atrogin1. In addition Murf1 provides an indirect estimate of protein degradation.

Interestingly, although, cisplatin induces $\mathrm{Nf}-\mathrm{KB}$ expression, the latter is increased in muscle in the presence of a tumor and is sufficient to trigger muscle wasting [43]: thus a mechanism is produced whereby chemotherapy induces Nf-kB dependent muscle wasting. The fact that NF-kB targets not only muscle fibers but also muscle stem cells [44] suggests that chemotherapy may reach multiple targets, in addition to muscle fiber protein metabolism. Indeed, the findings that NF-kB is involved in both tumor- and chemotherapy-induced muscle wasting suggested that common pathways are activated. This has been recently confirmed by the group of Andrea Bonetto, at Indiana University [45]. By using a comprehensive approach based on liquid chromatography followed by mass spectrometry they compared the skeletal muscle proteome in C26-tumor bearing and chemotherapy treated mice (chemotherapy consisting of 5-fluorouracil (5-FU), Leucovorin (LV) and CPT-11, a combination also known as Folfiri). Authors found that cancer and chemotherapy promote the down-regulation of 235 and 345 muscle proteins, respectively, the vast majority of which were modulated in common [45]. Mitochondrial dysfunction, TCA cycle, fatty acid metabolism, and $\mathrm{Ca} 2+$ signaling were among the altered pathways detected [45]. Further insights about muscle mitochondria dysregulation following chemotherapy came from the same group which proved that mitochondrial depletion is MAPK-dependent [46]. This is consistent with previous findings that muscle wasting is associated with up-regulation of ERK1/2 and p38 MAPKs [47]. In an elegant, recent study Bonetto and co-workers proposed the inhibition of the activin receptor $2 \mathrm{~B}$ (ACVR2B) signaling to counteract both cancerand chemotherapy-induced muscle wasting, by using ACVR2B/Fc, a soluble ACVR2B fusion protein and inhibitor of receptor downstream signaling [48]. ACVR2B/Fc was effective not only in counteracting Folfiri-induced skeletal muscle loss, but also the Folfiri negative effects on bone mass [48].

Given that cancer and chemotherapy activate common pathways in muscle and exercise has proven effective against cancer-induced muscle wasting, several research groups have been prompted to study whether physical activity can have beneficial effects during chemotherapy as well. Indeed, several epidemiological studies and clinical trials suggest that both resistance and endurance exercise should well be an integral part of supportive care for cancer patients undergoing chemotherapy [49-51]. Taken together these studies provide a rationale for using treatments to both counteract tumor growth and to reduce the side effects of chemotherapy.

The most relevant research on chemotherapy-induced muscle wasting are summarized in a recent review published in European Journal of Translation Myology [52]. The European Journal of Translation Myology has published many papers related to muscle wasting linked to mobility disorders [53-59], to muscle atrophy in sarcopenia and disease states [60-62], and to physical exercise [63, 64]. Originally devoted to biology, physiology, diagnostic, and to the rehabilitation of skeletal muscle tissue, the journal is now moving forward to cover additional fields in myology, thus taking on a broader medical and clinical interest. Exercise biological effects are usually reported in specialized journals, such as Sports Medicine [65] or The Physician and Sportsmedicine [66]. We suggest, instead, that a greater number of transdisciplinary journals, such as Biology, engineering and Medicine $[67,68]$ and European Journal of Translation Myology [69-71] dedicate original data articles and special issues to the effects of exercise with medical implications. This policy would give greater visibility to exercise training protocols for medical applications and would favor the incorporation of exercise into multimodal therapies against complex, multiorgan syndromes such as cachexia $[72,73]$.

\section{Conclusions}

The following conclusions can be drawn from the above: 1) cachexia is a severe complication of many pathologies, particularly cancer, but also a side effect of chemotherapy; 2) cachexia should be counteracted since it accounts for a significant percentage of deaths, it affects the patients' quality of life and interferes with therapy for the primary disease; 3) even though incomplete, current knowledge on the mechanisms of cachexia allows to set the goal of a therapy against cachexia, possibly acting at different levels of intervention; this is not in contrast with the fact that (4) the therapy of cachexia also consists in the primary disease therapy; 5) ideally, cachexia should be prevented rather than cured; 6) exercise may play a major role in both prevention of cachexia and rescue of lean mass, thanks to its systemic effects.

\section{References}

1. Baracos VE, Martin L, Korc M, Guttridge DC, Fearon KCH (2018) Cancer-associated cachexia. Nat Rev Dis Primers 4: 17105. [Crossref]

2. Onesti JK, Guttridge DC (2014) Inflammation based regulation of cancer cachexia. Biomed Res Int 2014: 168407. [Crossref]

3. Pedersen L, Idorn M, Olofsson GH, Lauenborg B, Nookaew I, et al. (2016) Voluntary Running Suppresses Tumor Growth through Epinephrine- and IL-6-Dependent NK Cell Mobilization and Redistribution. Cell Metab. 23:554-562. [Crossref]

4. Flint TR, Janowitz T, Connell CM, Roberts EW, Denton AE, et al. (2016) TumorInduced IL-6 Reprograms Host Metabolism to Suppress Anti-tumor Immunity. Cell Metab 24: 672-684. [Crossref]

5. Silvério R, Lira FS, Oyama LM, Oller do Nascimento CM, et al. (2017) Lipases and lipid droplet-associated protein expression in subcutaneous white adipose tissue of cachectic patients with cancer. Lipids Health Dis 16: 159. [Crossref]

6. Neves RX, Rosa-Neto JC, Yamashita AS, Matos-Neto EM, Riccardi DM, et al. (2016) White adipose tissue cells and the progression of cachexia: inflammatory pathways. $J$ Cachexia Sarcopenia Muscle 7: 193-203. [Crossref]

7. Berardi E, Aulino P, Murfuni I, Toschi A, Padula F, et al. (2008) Skeletal muscle is enriched in hematopoietic stem cells and not inflammatory cells in cachectic mice. Neurol Res 30: 160-169. [Crossref] 
8. Carotenuto F, Costa A, Albertini MC, Rocchi MB, Rudov A, et al. (2016) Dietary Flaxseed Mitigates Impaired Skeletal Muscle Regeneration: in Vivo, in Vitro and in Silico Studies. Int J Med Sci 13:206-219. [Crossref]

9. Moresi V, Pristerà A, Scicchitano BM, Molinaro M, Teodori L, et al. (2008) Tumor necrosis factor-alpha inhibition of skeletal muscle regeneration is mediated by a caspase-dependent stem cell response. Stem cells 26:997-1008. [Crossref]

10. Coletti D, Moresi V, Adamo S, Molinaro M, Sassoon D (2005) Tumor necrosis factoralpha gene transfer induces cachexia and inhibits muscle regeneration. Genesis 43:120128. [Crossref]

11. Tisdale MJ (2005) Molecular pathways leading to cancer cachexia. Physiology (Bethesda) 20: 340-348. [Crossref]

12. Barkhudaryan A, Scherbakov N, Springer J, Doehner W, et al. (2017) Cardiac muscle wasting in individuals with cancer cachexia. ESC Heart Fail 4: 458-467. [Crossref]

13. VanderVeen BN, Hardee JP, Fix DK, Carson JA (2018) Skeletal muscle function during the progression of cancer cachexia in the male ApcMin/+ mouse. J Appl Physiol (1985) 124: 684-695. [Crossref]

14. Anderson LJ, Liu H, Garcia JM (2017) Sex Differences in Muscle Wasting. Adv Exp Med Biol 1043: 153-197. [Crossref]

15. Acharyya S, Guttridge DC (2007) Cancer cachexia signaling pathways continue to emerge yet much still points to the proteasome. Clin Cancer Res 13: 1356-1361. [Crossref]

16. Salazar-Degracia A, Busquets S, Argilés JM, et al. (2017) Formoterol attenuates increased oxidative stress and myosin protein loss in respiratory and limb muscles of cancer cachectic rats. PeerJ 5: e4109. [Crossref]

17. Yoshimura M, Shiomi Y, Ohira Y, Takei M, Tanaka T (2017) Z-505 hydrochloride, an orally active ghrelin agonist, attenuates the progression of cancer cachexia via anabolic hormones in Colon 26 tumor-bearing mice. Eur J Pharmacol 811: 30-37. [Crossref]

18. von Haehling S, Ebner N, Dos Santos MR, Springer J, et al. (2017) Muscle wasting and cachexia in heart failure: mechanisms and therapies. Nat Rev Cardiol 14: 323-341. [Crossref]

19. Wang J, Bo X, Suo T, Liu H, Ni X, et al. (2018) Tumor-infiltrating neutrophils predict prognosis and adjuvant chemotherapeutic benefit in patients with biliary cancer. Cancer Sci. [Crossref]

20. Daly LE, Ní Bhuachalla ÉB, Power DG, Cushen SJ, James K, et al. (2018) Loss of skeletal muscle during systemic chemotherapy is prognostic of poor survival in patients with foregut cancer. J Cachexia Sarcopenia Muscle 9:315-325. [Crossref]

21. Weekers F, Van den Berghe G (2004) Endocrine modifications and interventions during critical illness. The Proc Nutr Soc 63:443-450. [Crossref]

22. Kalantar-Zadeh K, Rhee C, Sim JJ, Stenvinkel P, Anker SD, et al. (2013) Why cachexia kills: examining the causality of poor outcomes in wasting conditions. $J$ Cachexia Sarcopenia Muscle 4: 89-94. [Crossref]

23. Tsoli M, Schweiger M, Vanniasinghe AS, Painter A, Zechner R, et al. (2014) Depletion of white adipose tissue in cancer cachexia syndrome is associated with inflammatory signaling and disrupted circadian regulation. PLoS One 9: e92966. [Crossref]

24. Ramos Lima MM, de Mello MA, \& Curi R (2002) Walker 256 tumour growth causes marked changes of glutamine metabolism in rat small intestine. Cell biochemistry and function 20:107-113.

25. Lira FS, Rosa JC, Zanchi NE, Yamashita AS, Lopes RD, et al. (2009) Regulation of inflammation in the adipose tissue in cancer cachexia: effect of exercise. Cell Biochem Funct 27: 71-75. [Crossref]

26. Lira FS, Antunes Bde M, Seelaender M, Rosa Neto JC (2015) The therapeutic potential of exercise to treat cachexia. Curr Opin Support Palliat Care 9: 317-324. [Crossref]

27. Rubin DA, Hackney AC (2010) Inflammatory cytokines and metabolic risk factors during growth and maturation: influence of physical activity. Med Sport Sci 55: 43-55. [Crossref]

28. Beavers KM, Brinkley TE, Nicklas BJ (2010) Effect of exercise training on chronic inflammation. Clinica chimica acta; Clin Chim Acta 411:785-793. [Crossref]

29. Evans WJ, Roubenoff R, Shevitz A (1998) Exercise and the treatment of wasting: aging and human immunodeficiency virus infection. Semin Oncol. 25:112-122. [Crossref]

30. Häkkinen A, Pakarinen A, Hannonen P, Kautiainen H, Nyman K, et al. (2005) Effects of prolonged combined strength and endurance training on physical fitness, body composition and serum hormones in women with rheumatoid arthritis and in healthy controls. Clin Exp Rheumatol.23:505-512. [Crossref]
31. Alessio HM, Goldfarb AH, Cao G (1997) Exercise-induced oxidative stress before and after vitamin C supplementation. Int J Sport Nutr 7: 1-9. [Crossref]

32. Acharyya S, Butchbach ME, Sahenk Z, Wang H, Saji M, et al. (2005) Dystrophin glycoprotein complex dysfunction: a regulatory link between muscular dystrophy and cancer cachexia. Cancer cell 8:421-432. [Crossref]

33. Perniconi B, et al. (2008) A meta-analysis on a therapeutic dilemma: to exercise or not to exercise in cachexia. Basic Applied Myology 18:115-120.

34. Pigna E, Berardi E, Aulino P, Rizzuto E, et al. (2016) Aerobic Exercise and Pharmacological Treatments Counteract Cachexia by Modulating Autophagy in Colon Cancer. Sci Rep 6: 26991. [Crossref]

35. Barone R, Macaluso F, Sangiorgi C, et al. (2016) Skeletal muscle Heat shock protein 60 increases after endurance training and induces peroxisome proliferator-activated receptor gamma coactivator $1 \hat{\mathrm{I}} \pm 1$ expression. Sci Rep 6: 19781. [Crossref]

36. Coletti D, Aulino P, Pigna E, Barteri F, Moresi V, et al. (2016) Spontaneous Physical Activity Downregulates Pax7 in Cancer Cachexia. Stem Cells Int 2016: 6729268. [Crossref]

37. Maddocks M, Jones LW, Wilcock A (2013) Immunological and hormonal effects of exercise: implications for cancer cachexia. Curr Opin Support Palliat Care. 7:376-382. [Crossref]

38. Maddocks M, Murton AJ, Wilcock A (2012) Therapeutic exercise in cancer cachexia. Crit Rev Oncog 17:285-292.

39. Lira FS, Neto JC, Seelaender M (2014) Exercise training as treatment in cancer cachexia. Appl Physiol Nutr Metab. 39:679-686.

40. Aulino P, Berardi E, Cardillo VM, Rizzuto E, Perniconi B, et al. (2010) Molecular, cellular and physiological characterization of the cancer cachexia-inducing $\mathrm{C} 26$ colon carcinoma in mouse. BMC Cancer 10: 363. [Crossref]

41. Tilignac T, Temparis S, Combaret L, Taillandier D, Pouch MN, et al. (2002) Chemotherapy inhibits skeletal muscle ubiquitin-proteasome-dependent proteolysis. Cancer Res 62:2771-2777. [Crossref]

42. Samuels SE, Knowles AL, Tilignac T, Debiton E, Madelmont JC, et al. (2001) Higher skeletal muscle protein synthesis and lower breakdown after chemotherapy in cachectic mice. Am J Physiol Regul Integr Comp Physiol 281: R133-139. [Crossref]

43. Cai D, Frantz JD, Tawa NE Jr, Melendez PA, Oh BC, et al. (2004) IKKbeta/NFkappaB activation causes severe muscle wasting in mice. Cell 119: 285-298. [Crossref]

44. He WA, Berardi E, Cardillo VM, Acharyya S, Aulino P, et al. (2013) NF-kappaBmediated $\operatorname{Pax} 7$ dysregulation in the muscle microenvironment promotes cancer cachexia. J Clin Invest 123: 4821-4835. [Crossref]

45. Barreto R, Mandili G, Witzmann FA, Novelli F, Zimmers TA, et al. (2016) Cancer and Chemotherapy Contribute to Muscle Loss by Activating Common Signaling Pathways. Front Physiol 7: 472. [Crossref]

46. Barreto R, Waning DL, Gao H, et al. (2016) Chemotherapy-related cachexia is associated with mitochondrial depletion and the activation of ERK1/2 and p38 MAPKs. Oncotarget 7: 43442-43460. [Crossref]

47. Liu Q, Xu WG, Luo Y, Han FF, Yao XH, et al. (2011) Cigarette smoke-induced skeletal muscle atrophy is associated with up-regulation of USP-19 via p38 and ERK MAPKs. J Cell Biochem 112: 2307-2316. [Crossref]

48. Barreto R, Kitase Y, Matsumoto $\mathrm{T}$, et al. (2017) ACVR2B/Fc counteracts chemotherapy-induced loss of muscle and bone mass. Sci Rep 7: 14470. [Crossref]

49. Schmidt ME, Wiskemann J, Armbrust P, Schneeweiss A, Ulrich CM, et al. (2015) Effects of resistance exercise on fatigue and quality of life in breast cancer patients undergoing adjuvant chemotherapy: A randomized controlled trial. International journal of cancer 137:471-480. [Crossref]

50. Courneya KS, Segal RJ, Mackey JR, Gelmon K, Friedenreich CM, et al. (2014) Effects of exercise dose and type on sleep quality in breast cancer patients receiving chemotherapy: a multicenter randomized trial. Breast Cancer Res Treat. 144:361-369. [Crossref]

51. Adamsen L, Quist M, Andersen C, Møller T, Herrstedt J, et al. (2009) Effect of a multimodal high intensity exercise intervention in cancer patients undergoing chemotherapy: randomised controlled trial. $B M J 339$ : b3410. [Crossref]

52. D C (2018) Chemotherapy-induced muscle wasting: an update. Eur J Transl Myol 28:5.

53. Carraro U, Coletti D, Kern H (2014) The Ejtm Specials "The Long-Term Denervated Muscle". Eur J Transl Myol 24: 3292. [Crossref] 
54. Sajer S (2017) Mobility disorders and pain, interrelations that need new research concepts and advanced clinical commitments. Eur J Transl Myol 27: 7179. [Crossref]

55. Pette D, Vrbová G (2017) The Contribution of Neuromuscular Stimulation in Elucidating Muscle Plasticity Revisited. Eur J Transl Myol 27: 6368. [Crossref]

56. Merico A, Cavinato M, Gregorio C, Lacatena A, Gioia E, et al. (2018) Effects of combined endurance and resistance training in Amyotrophic Lateral Sclerosis: A pilot, randomized, controlled study. Eur J Transl Myol 28: 7278. [Crossref]

57. Pigna E, Greco E, Morozzi G, Grottelli S, Rotini A, et al. (2017) Denervation does not Induce Muscle Atrophy Through Oxidative Stress. Eur J Transl Myol 27: 6406. [Crossref]

58. Mosole S, Carraro U, Kern H, Loefler S, Zampieri S (2016) Use it or Lose It: Tonic Activity of Slow Motoneurons Promotes Their Survival and Preferentially Increases Slow Fiber-Type Groupings in Muscles of Old Lifelong Recreational Sportsmen. Eur J Transl Myol 26: 5972. [Crossref]

59. Carraro U, Kern H (2016) Severely Atrophic Human Muscle Fibers With Nuclear Misplacement Survive Many Years of Permanent Denervation. Eur J Transl Myol 26: 5894. [Crossref]

60. Barber L, Scicchitano BM, Musaro A (2015) Molecular and Cellular Mechanisms of Muscle Aging and Sarcopenia and Effects of Electrical Stimulation in Seniors. Eur $J$ Transl Myol 25: 231-236. [Crossref]

61. Hockerman GH, Dethrow NM, Hameed S, Doran M, Jaeger C, et al. (2014) The Ubr2 Gene is Expressed in Skeletal Muscle Atrophying as a Result of Hind Limb Suspension, but not Merg1a Expression Alone. Eur J Transl Myol 24: 3319. [Crossref]

62. Costa A, Rossi E, Scicchitano BM, Coletti D, Moresi V, et al. (2014) Neurohypophyseal Hormones: Novel Actors of Striated Muscle Development and Homeostasis. Eur J Transl Myol 24: 3790. [Crossref]

63. Zampieri S, Mosole S, Löfler S, Fruhmann H, Burggraf S, et al. (2015) Physical Exercise in Aging: Nine Weeks of Leg Press or Electrical Stimulation Training in 70 Years Old Sedentary Elderly People. Eur J Transl Myol 25:237-242. [Crossref]
64. Coletti D, Adamo S, \& Moresi V (2017) Of Faeces and Sweat. How Much a Mouse is Willing to Run: Having a Hard Time Measuring Spontaneous Physical Activity in Different Mouse Sub-Strains. Eur J Transl Myol 27:6483. [Crossref]

65. Millar PJ, McGowan CL, Cornelissen VA, Araujo CG, Swaine IL (2014) Evidence for the role of isometric exercise training in reducing blood pressure: potential mechanisms and future directions. Sports med 44:345-356. [Crossref]

66. Schwartz AL, Biddle-Newberry M, de Heer HD (2015) Randomized trial of exercise and an online recovery tool to improve rehabilitation outcomes of cancer survivors. Phys Sportsmed. 43:143-149. [Crossref]

67. Marcante A (2017) Modulation of trophism and fiber type gene expression in denervated muscle activated by different patterns of electrical stimulation. Role of muscle fiber regeneration revisited in 2017. Biol Eng Med 2.

68. Y S (2018) Myotube cell-based 2D-SPR sensor for insulin and its analog detection. Biol Eng Med 3.

69. Zampieri S, Doria A, Adami N, Biral D, Vecchiato M, et al. (2010) Subclinical myopathy in patients affected with newly diagnosed colorectal cancer at clinical onset of disease: evidence from skeletal muscle biopsies. Neurological research 32:20-25. [Crossref]

70. Veneziani S, Doria C, Falciati L, Castelli CC, Illic GF5 (2014) Return to Competition in a Chronic Low Back Pain Runner: Beyond a Therapeutic Exercise Approach, a Case Report. Eur J Transl Myol 24: 2221. [Crossref]

71. Carraro U, Kern H, Gava P, Hofer C, Loefler S, et al. (2015) Biology of Muscle Atrophy and of its Recovery by FES in Aging and Mobility Impairments: Roots and By-Products. Eur J Transl Myol. 25:221-230. [Crossref]

72. Antunes BM, Lira FS, Pimentel GD, Rosa Neto JC, Esteves AM, et al. (2015). Hypothalamic energy metabolism is impaired by doxorubicin independently of inflammation in non-tumour-bearing rats. Cell Biochem Funct 33(6):394-7.

73. Batatinha HA, Lima EA, Teixeira AA, Souza CO, Biondo LA, et al. (2017) Association Between Aerobic Exercise and Rosiglitazone Avoided the NAFLD and Live Inflammation Exacerbated in PPAR- $\alpha$ Knockout Mice. JCell Physiol.232(5):1008-1019.

Copyright: $\odot 2018$ Coletti D. This is an open-access article distributed under the terms of the Creative Commons Attribution License, which permits unrestricted use, distribution, and reproduction in any medium, provided the original author and source are credited. 